\title{
Review: inhaled corticosteroids for asthma or chronic obstructive pulmonary disease do not increase bone loss
}

Jones A, Fay JK, Burr M, et al. Inhaled corticosteroid effects on bone metabolism in asthma and mild chronic obstructive pulmonary disease. Cochrane Database Syst Rev 2002;(1):CD003537 (latest version 11 Oct 2001).

\section{QUESTION: In patients with asthma or chronic obstructive pulmonary disease (COPD), do inhaled corticosteroids increase bone fractures, reduce bone mineral density (BMD), or change specified biochemical markers?}

\section{Data sources}

Studies were identified by searching Medline, EMBASE/ Excerpta Medica, CINAHL, Science Citation Index, and the Cochrane Controlled Trials Register (to July 2001); searching key journals and bibliographies of relevant studies; and contacting authors and pharmaceutical companies.

\section{Study selection}

Studies in any language were selected if they were randomised controlled trials that compared inhaled corticosteroids with placebo in patients with or without a clinical diagnosis of asthma or COPD.

\section{Data extraction}

Data were extracted on patients, drug regimens, and outcomes. 2 reviewers independently assessed the quality of study methods.

Sources of funding: Wales Office of

Research and

Development for Health and Social Care; National Assembly for Wales, UK; Garfield Weston Foundation $U K$.

For correspondence: Dr A Jones, University of Wales College of Medicine, Cardiff, Wales, UK.

research@ gors.freeserve.co.uk

\section{Main results}

7 studies met the selection criteria. 4 studies recruited patients with mild asthma or COPD (1870 patients, $67 \%$ men), and 3 studies recruited healthy volunteers (119 people, $66 \%$ women). Duration of follow up ranged from 6 weeks to 3 years. Inhaled corticosteroids used were beclomethasone, budesonide, and fluticasone. Inhaled corticosteroids at all doses did not differ from placebo for vertebral fractures (2 studies); change in BMD (3 studies); or concentrations of osteocalcin (3 studies), C-terminal propeptide of type-one pro collagen ( 1 study), parathyroid hormone (1 study), alkaline phosphatase (1 study), or urinary hydroxyproline (1 study) (table).

Inhaled corticosteroids $v$ placebo for asthma or chronic obstructive pulmonary disease*

\begin{tabular}{|c|c|c|c|}
\hline \multirow{2}{*}{$\begin{array}{l}\text { Outcomes at } 6 \text { weeks } \\
\text { to } 3 \text { years }\end{array}$} & \multicolumn{2}{|c|}{ Weighted event rates } & \multirow[b]{2}{*}{ RRI (95\% Cl) } \\
\hline & Corticosteroids & Placebo & \\
\hline \multirow[t]{3}{*}{ Vertebral fracture } & $1.3 \%$ & $0.73 \%$ & $67 \%(-54$ to 512$)$ \\
\hline & \multicolumn{2}{|c|}{ Weighted means } & \multirow{2}{*}{$\begin{array}{l}\text { Weighted mean } \\
\text { difference }(\mathbf{C I})\end{array}$} \\
\hline & Corticosteroids & Placebo & \\
\hline Change in BMD & $1.21 \%$ & $1.20 \%$ & $0.02 \%(-0.08$ to 0.11$)$ \\
\hline $\begin{array}{l}\text { Parathyroid hormone } \\
(\mathrm{mcg} / \mathrm{l}) \dagger\end{array}$ & 10.5 & 18.0 & $-7.5(-16$ to 0.73$)$ \\
\hline $\mathrm{PICP}(\mathrm{mcg} / \mathrm{l}) \dagger$ & 128.5 & 117.0 & $11.6(-3.1$ to 26$)$ \\
\hline $\begin{array}{l}\text { Urinary hydroxyproline } \\
(\mu \mathrm{mol} / \mathrm{l} \mathrm{GF}) \dagger\end{array}$ & 1.6 & 1.7 & $-0.08(-0.53$ to 0.37$)$ \\
\hline $\begin{array}{l}\text { Alkaline phosphatase } \\
(\mathrm{IU} / \mathrm{I}) \dagger\end{array}$ & 43 & 54 & $-11(-25$ to 3.3$)$ \\
\hline & & & $\begin{array}{l}\text { Standardised mean } \\
\text { difference }(\mathrm{Cl})\end{array}$ \\
\hline Osteocalcin & & & $-0.34(-0.72$ to 0.04$)$ \\
\hline
\end{tabular}

${ }^{*} \mathrm{BMD}=$ bone mineral density; $\mathrm{PICP}=\mathrm{C}$-terminal propeptide of type-one pro collagen. Other abbreviations defined in glossary; weighted events, RRI, $\mathrm{NNH}$, and $\mathrm{Cl}$ calculated from data in article using a fixed effects model. No mean differences were statistically significant.

†Means and mean differences not weighted.

\section{Conclusion}

In patients with asthma or chronic obstructive pulmonary disease, inhaled corticosteroids do not increase vertebral fractures, reduce bone mineral density, or change biochemical markers.

\section{COMMENTARY}

Osteoporosis is one of the most serious complications of systemic steroid treatment, and changes in BMD are detectable within a few months of starting treatment. The reduction in $\mathrm{BMD}$ is a sensitive but non-specific predictor of risk for future fracture. ${ }^{1}$ Inhaled corticosteroids have revolutionised the treatment of asthma for the past 30 years by improving symptoms, reducing the frequency of exacerbations, and preventing deaths from asthma. Because they are so effective, most guidelines recommend that they have a central role in the management of all but the most minor degrees of asthma. In COPD, the benefits are more marginal, but the small reduction in the exacerbation rate has led many clinicians to recommend long term use. Many millions of patients worldwide are now taking large doses of potent, expensive corticosteroids for years on end. How safe is this practice, and can we really reassure patients that the bone thinning effect of systemic steroids does not occur when the same class of compound is received via an inhaler? Studies with the osteoporotic fracture rate as a primary end point take many years to complete and need to be adequately powered to detect what may be a fairly low likelihood event (depending on the population studied).

The systematic review by Jones et al concluded that, overall, no obvious increased risk existed for fracture, reduction in bone density, or change in any of the biochemical surrogates of increased bone turnover. Measurement of biochemical markers of bone formation was studied for mere weeks, although studies measuring BMD and fracture rate were of necessity much longer. Doses in some of the studies exceeded the maximum recommended amount, and these studies showed evidence for a greater effect on bone turnover. The pharmacokinetics of individual delivery systems and the pharmacology of various steroids inevitably introduced a degree of heterogeneity, and most study patients were young and at low risk for osteoporosis. The recently published Lung Health Study Research Group trial of inhaled triamcinolone in COPD was not included in this review, but changes in bone density at the lumbar spine and femur were apparent at 3 years of follow up, which strikes a note of caution. ${ }^{2}$

Although this review provides some reassurance about the effectiveness and safety of inhaled corticosteroids, the issue is far from settled, and much longer follow up and treatment periods are required before such medication can be declared risk free.

Michael Greenstone, MD Castle Hill Hospital, Hull, UK

1 NIH Consensus Development Panel on Osteoporosis Prevention, Diagnosis, and Therapy. Osteoporosis prevention, diagnosis, and therapy. JAMA 2001;285:785-95.

2 The Lung Health Study Research Group. Effect of inhaled triamcinolone on the decline in pulmonary function in triamcinolone on the decline in pulmonary function in 2000;343:1902-9. 